\title{
Angioplasty Induced Cephalic Arch Rupture
}

\section{Quencer KB*}

Department of Radiology, University of California-San Diego, USA

*Corresponding author: Quencer KB, Department of Radiology, University of California-San Diego 200 W. Arbor Drive San Diego, CA 92103, USA

Received: April 24, 2017; Accepted: May 16, 2017; Published: May 29, 2017

\begin{abstract}
Per Kidney Disease Outcome Quality Initiative (KDOQI) guidelines the second most preferred dialysis access, after the radiocephalicarterio-venous fistula (AVF), is the upper arm brachiocephalic AVF. Stenosis within the cephalic arch, the central most portion of the cephalic vein, occurs in up to $75 \%$ of dysfunctional brachiocephalic AVFs. While angioplasty is the first line treatment, subsequent patency is low. Additionally, angioplasty at this site is more commonly complicated by vessel rupture than at other sites within AV accesses. We describe a case of a 76 year-old female with end-stage renal disease (ESRD) undergoing a fistula gram and angioplasty of cephalic arch stenosis that resulted in vessel rupture. It was successful treated with prolonged balloon inflation. Cephalic arch stenosis, its etiologies, treatments are briefly reviewed. Additionally, management of angioplasty induced vessel rupture during fistulography is discussed.
\end{abstract}

Keywords: Cephalic arch; Angioplasty; Vessel rupture

\section{Abbreviations}

KDOQI: Kidney Disease Outcome Quality Initiative; AVF: Arterio-Venous Fistula; ESRD: End-Stage Renal Disease; PTFE: Polytetraflouroethylene; mm-millimeter

\section{Case Presentation}

A 76 y/o F with a past medical history of ESRD secondary to hypertension had a left upper arm brachiocephalic fistula created 15 months prior to our procedure. The AVF was first used 7 weeks after its creation. Ten weeks later, focal false aneurysm and associated hematoma developed at a cannulation site. This was treated by placement of a $6 \mathrm{~mm}$ polytetraflouroethylene (PTFE) interposition graft. The AVF continued to work well for another 10 months but low flows, poor clearance and prolonged bleeding subsequently developed. She was therefore referred to interventional radiology for fistula gram and possible intervention.

Initial antegrade angiogram (Figure 1) showed moderate cephalic arch stenosis. After sizing the balloon to match the diameter normal caliber adjacent cephalic vein segment, angioplasty was performed with a 7 millimeter $(\mathrm{mm})$ diameter high-pressure balloon (Conquest Bard PV) (Figure 2). The balloon and wire were pulled back and a repeat angiogram showed significant extravasation at the site of angioplasty consistent with vessel disruption (Figure 3). A wire and balloon were successfully re-negotiated across this site of disruption low-pressure inflation was done for 5 minutes (Figure 4). Repeat angiogram showed cessation of contrast extravasation and good flow through the cephalic arch (Figure 5).

\section{Discussion}

Approximately $65 \%$ of ESRD in the United States patients dialyze through an arterio-venous fistula [1]. Per KDOQI guidelines, the most preferred AVF is a radio-cephalic fistula [2]. The second most preferred AVF is a brachiocephalic fistula, which involves connecting the side of the brachial artery to the end of the cephalic vein above the elbow [2]. While maturation rates and flow volumes are higher when

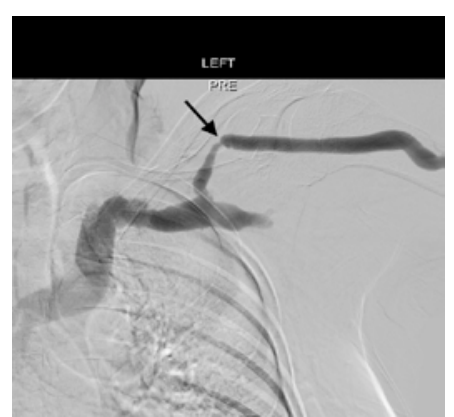

Figure 1: Initial angiogram shows focal moderate stenosis in the cephalic arch (black arrow).

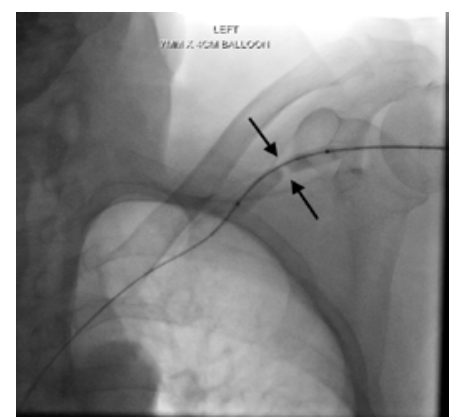

Figure 2: Spot fluoroscopic image during insufflation showing focal waist in the balloon at the site of stenosis.

compared to the forearm radiocephalic fistula, the 5-20x increased rate of steal syndrome and the preclusion of subsequent forearm fistula creation makes it less desirable than creation of a radiocephalic fistula $[3,4]$.

Stenosis inevitably develops within any arterio-venous access. For the brachiocephalic fistula, it most commonly occurs within the cephalic arch, which is defined as the central most part of the cephalic vein as turns into meet the axillary vein, forming the subclavian 


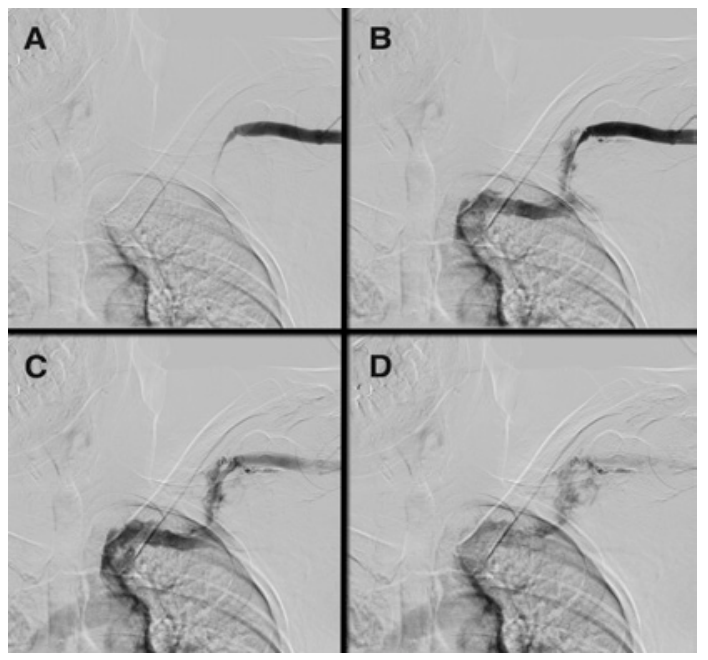

Figure 3: Four sequential angiographic images after balloon dilation show significant luminal narrowing within the cephalic arch (A) followed by significant extraluminal contrast accumulation consistent with extravasation and vessel rupture (B-D).

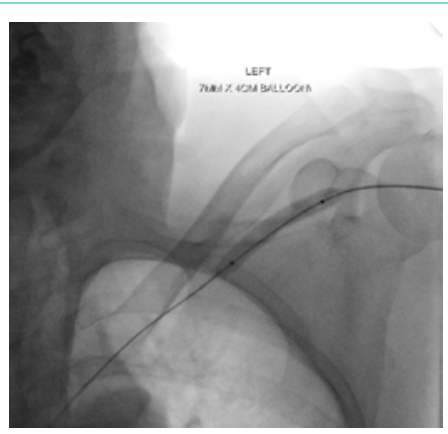

Figure 4: A wire was then re-negotiated through the site of extravasation and into the SVC. Over this wire a $7 \mathrm{~mm}$ balloon was inflated at low pressure for 5 minutes.

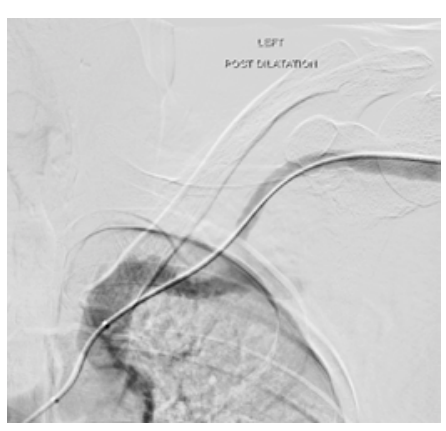

Figure 5: Repeat angiogram now shows resolution of the contrast extravasation and interval improvement in luminal diameter from the initial angiogram.

vein. Stenosis at this site occurs in up to $75 \%$ of dysfunctional brachiocephalic fistulas [5]. Multiple factors contribute to the development of stenosis at this site including turbulent flow, given its arching configuration, high concentration of venous valves and extrinsic compression by surrounding clavipectoral fascia [6,7].

Cephalic arch stenosis leads to typical signs of outflow stenosis including elevated venous pressures, abnormal increased pulsatility, prolonged bleeding after dialysis, slow flows and, if severe enough it can cause access thrombosis [8]. Standard treatment consists of balloon angioplasty, although patency after this is $23 \%$ at 1 year [9], below KDOQI target and patency at other sites [2]. Other potential treatments include stent graft placement, intentional flow reduction and surgical turndown of the cephalic vein to the axillary vein [10$12]$.

In addition to being an obstinate site to treat, a significantly higher rate of vessel rupture after angioplasty occurs. Vessel disrupution has been reported to occur between 6 [13] and 15\% [14] of angioplasties at this site, compared to less than $2 \%$ at other sites [15]. This higher rate of rupture is possibly due to the need for higher pressure balloons at this site [6]. Initial treatment of angioplasty induced venous rupture is prolonged (3-5 minute), low pressure (2-5 atmospheres) balloon inflation [16]. If extravasation persists after the first inflation, this can be repeated two more times or consideration can be given to stent graft placement [17]. Essential to employing eithier technique is maintaining a guidewire across the site of stenosis/extravasation. If a guidewire is not maintained or cannot be negotiated across the site of extravasation, intentional ligtation, thrombosis or coil embolization may become necessary to control the site of bleeding.

\section{Conclusion}

The cephalic arch is a frequent site of stenosis in brachiocephalic fistulas and, although first line treatment is angioplasty, patency rates are lower and rates of vascular rupture are higher than at other sites. The two mainstays of angioplasty induced vessel rupture during fistula grams are prolonged balloon inflation and, if necessary, the placement of a covered stent across the site of extravasation. This case illustrates this known complication of cephalic arch angioplasty and how to treat it. One lesson to be learned is to always maintain guide wire access across the site of stenosis and angioplasty until repeat angiogram is performed.

\section{References}

1. Saran R, Robinson B, Abbott KC, Agodoa LY, Ayanian J, Bragg-Gresham J US Renal Data System 2016 Annual Data Report: Epidemiology of Kidney Disease in the United States. Am J Kidney Dis. 2017; 69: A7-A8.

2. Vascular Access Work G. Clinical practice guidelines for vascular access. Am J Kidney Dis. 2006; 48: S176-247.

3. Dixon BS, Novak L, Fangman J. Hemodialysis vascular access survival: upper-arm native arteriovenous fistula. Am J kidney Dis. 2002; 39: 92-101.

4. Quencer KB, Arici M. Arteriovenous Fistulas and Their Characteristic Sites of Stenosis. AJR Am J Roentgenol. 2015; 205: 726-734.

5. Hammes M, Funaki B, Coe FL. Cephalic arch stenosis in patients with fistula access for hemodialysis: relationship to diabetes and thrombosis. Hemodialysis int. 2008; 12: 85-89.

6. Daoui R, Asif A. Cephalic arch stenosis: mechanisms and management strategies. Semin Nephrol. 2012; 32: 538-544.

7. Boghosian M, Cassel K, Hammes M, Funaki B, Kim S, Qian X, et al. Hemodynamics in the cephalic arch of a brachiocephalic fistula. Med Eng Phys. 2014; 36: 822-830.

8. Quencer KB, Kidd J, Kinney T. Preprocedure Evaluation of a Dysfunctional Dialysis Access. Tech Vasc Interv Radiol. 2017; 20: 20-30.

9. Rajan DK, Clark TW, Patel NK, Stavropoulos SW, Simons ME. Prevalence and treatment of cephalic arch stenosis in dysfunctional autogenous hemodialysis fistulas. J Vasc Interv Radiol. 2003; 14: 567-573. 
10. Rajan DK, Falk A. A Randomized Prospective Study Comparing Outcomes of Angioplasty versus VIABAHN Stent-Graft Placement for Cephalic Arch Stenosis in Dysfunctional Hemodialysis Accesses. J Vasc Interv Radiol. 2015; 26: 1355-1361.

11. Chen JC, Kamal DM, Jastrzebski J, Taylor DC. Venovenostomy for outflow venous obstruction in patients with upper extremity autogenous hemodialysis arteriovenous access. Ann Vasc Surg. 2005; 19: 629-635.

12. Miller GA, Friedman A, Khariton A, Preddie DC, Savransky Y. Access flow reduction and recurrent symptomatic cephalic arch stenosis in brachiocephalic hemodialysis arteriovenous fistulas. J Vasc Access. 2010; 11: 281-287.

13. Rajan DK, Bunston S, Misra S, Pinto R, Lok CE. Dysfunctional autogenous hemodialysis fistulas: outcomes after angioplasty--are there clinical predictors of patency? Radiology. 2004; 232: 508-515
14. Turmel-Rodrigues L, Pengloan J, Baudin S, Testou D, Abaza M, Dahdah G. Treatment of stenosis and thrombosis in haemodialysis fistulas and grafts by interventional radiology. Nephrol Dial Transplant. 2000; 15: 2029-2036.

15. Pappas JN, Vesely TM. Vascular rupture during angioplasty of hemodialysis raft-related stenoses. J Vasc Access. 2002; 3: 120-126.

16. Rundback JH, Leonardo RF, Poplausky MR, Rozenblit G. Venous rupture complicating hemodialysis access angioplasty: percutaneous treatment and outcomes in seven patients. AJR Am J Roentgenol. 1998; 171: 1081-1084.

17. Dale JD, Dolmatch BL, Duch JM, Winder R, Davidson IJ. Expanded polytetrafluoroethylene-covered stent treatment of angioplasty-related extravasation during hemodialysis access intervention: technical and 180day patency. J Vasc Interv Radiol. 2010; 21: 322-326.
Austin J Nephrol Hypertens - Volume 4 Issue 1 - 2017

ISSN : 2381-8964 | www.austinpublishing group.com

Quencer. (C) All rights are reserved
Citation: Quencer KB. Angioplasty Induced Cephalic Arch Rupture. Austin J Nephrol Hypertens. 2017; 4(1): 1065. 